\title{
Autism and Triadic Play: An Object Lesson in the Mutuality of the Social and Material
}

\section{Emma I. Williams, Alan Costall \& Vasu Reddy}

To cite this article: Emma I. Williams, Alan Costall \& Vasu Reddy (2018): Autism and Triadic Play: An Object Lesson in the Mutuality of the Social and Material, Ecological Psychology, DOI: 10.1080/10407413.2018.1439140

To link to this article: https://doi.org/10.1080/10407413.2018.1439140

Accepted author version posted online: 13 Feb 2018.

\section{世} Submit your article to this journal

III Article views: 11

Q View related articles $\square$

View Crossmark data ¿ 
Publisher: Routledge

Journal: Ecological Psychology

DOI: https://doi.org/10.1080/10407413.2018.1439140

Running head: MUTUALITY OF THE SOCIAL AND MATERIAL

Autism and Triadic Play: An Object Lesson in the Mutuality of the Social and Material

Emma I. Williams

The University of Surrey, II

Alan Costall

The University of Porisinouth, UK

Vasu Redíy

The University of Portsmouth, UK

Author note

Emma I. Wiliams, School of Psychology, Faculty of Health and Medical Sciences, University of Surrey, Guildford

This research was supported by a grant from the Economic and Social Research Council (R00023 4949). The author would like to thank Zita Bareham for her invaluable assistance in coding the play sessions and the reviewers for their very helpful comments on earlier drafts of the paper.

Correspondence should be addressed to Emma I. Williams, School of Psychology, Faculty of Health and Medical Sciences, University of Surrey, Guildford, GU2 7XH

Contact: e.i.williams@surrey.ac.uk

\section{Abstract}

Children's relations to objects are often seen as operating in a physical, asocial, realm distinct from the sociocultural realm of other people. The most influential theories of autism exemplify this assumption, emphasising problems in relating to other people alongside relatively intact dealings with objects. This 
paper challenges the notion of a rigid social-material divide. It examines evidence of widespread disruption in the object use of children with autism, alongside developmental ecological and sociocultural research highlighting the mutuality of our relations to people and things, to argue that difficulties in relating to other people should themselves lead us to expect corresponding problems in object use.

In support of this argument findings are presented from an empirical study comparing the triadic (parent-object-infant) play of children with autism (aged 1-6) and their parents to that of developmentally matched typical and Down syndrome dyads. Children's response to parentai invitations and the proportion of time each child spent engaged with objects and/gri then parents were compared. In contrast to the children in the comparison groups, those with antism were more likely to ignore parental invitations, or be preoccupied with their own use of an object. They also spent less time jointly engaged with their parent and an object and more time unengaged or focussed exclusively on their own use of an object. These findings are discussed in the context of Gibson's concept of affordances to further our understanding of the social mediation of object use in autistic and non-autistic children, and the role unusla! child-object relations in autism might play in disrupting on-going interaction.

Keywords: triadic play; autism spectrum disorder; children; object use; social-material divide; sociocultural; ecological psychology; affordances; mutuality.

Autism and triadic play: An object lesson in the mutuality of the social and material In developmental psychology children's relations to objects have tended to be seen as operating in a physical, asocial, realm as distinct from the sociocultural realm of other people. This material-social dualism results from a propensity in psychology as a whole to limit conceptions of the 'social' only to person-to-person interactions, as if we lived in "a world of actors devoid of things" (Joerges, 1988, p. 220; Costall \& Dreier, 2006; Williams \& Costall, 2000). Furthermore, the psychological importance of objects has tended to be underplayed with many psychologists appearing to be convinced that the only 
real 'object' of study is, not what people actually do and the material conditions of this action, but the internal structures and processes underlying human agency (Costall \& Dreier, 2006). A material-social divide, as well as neglect of material culture, is clearly evident in the most influential theories of dysfunction in autism (Baron-Cohen, Leslie \& Frith, 1985; Leslie, 1987; Baron-Cohen, 1989a; 1995; 2008; Wimmer \& Perner, 1983). These have tended to focus almost exclusively on the difficulties children with autism spectrum disorder (ASD) have with other people, whilst saying relatively littie about object use, other than the special case of pretend play that is seen as providing an 'index' of a supposedly disembodied capacity for symbolism.

This paper challenges the notion of a rigid separation between the social and ?naterial in children's developing understanding and use of objects, drawing on evidence of the widespread disruption of object use in autism extending well beyond the special case of pretend play (Williams, 2003; Wilson et al., 2017), and on research and theory from deveipmentai ecological psychology and sociocultural psychology that highlights the reciprocity of our relationships to people and things (Costall, 2012; Costall and Dreier, 2006; Leontiev, 1981; Preston, 2000; Szokolszky, 2006; Valsiner, 1987; Williams \& Costall, 2000). Both the developmental ecological and sociocultural approaches highlight the key role that other people piay in introducing children to the 'proper' use of everyday objects in the context of daily routries and play, whilst these same objects, in turn, shape our human practices in shared ways and are an eriduring source of social influence. In light of evidence of widespread disruption in object use in ASD and the interpenetration of the social and material, a comparative examination of the triadic (parent-child-object) play of children with ASD and their parents to that of developmentally matched control dyads was undertaken with the aim of examining the impact, if any, of unusual relations to objects on the ability of parents and their children with ASL to velate to each other through objects.

\section{Psychological theories of autism and the material-social divide}

In his seminal paper, identifying 'early childhood autism' as a distinct clinical entity for the first time, Leo Kanner (1943) characterises the condition as one involving a specific impairment in interpersonal relatedness that leaves object use relatively unaffected. The combination of widespread difficulties in relating to other people alongside "excellent, purposeful and 'intelligent"” (Kanner, 1943; 
p. 246) relations to objects continues to figure centrally within the 'Theory of Mind' account of dysfunction in autism (Baron-Cohen, Leslie \& Frith, 1985; Leslie, 1987; Baron-Cohen, 2008) that has been credited with bringing developmental psychology into mainstream autism research (Rajendran \& Mitchell, 2007). This approach, which has proliferated in developmental psychology from the 1980's onwards, has been by far the most influential cognitive theory of autism for researchers and practitioners (Rajendran \& Mitchell, 2007). Its original formulation contends that individuals with ASD have a primary cognitive deficit required for second-order (meta-) representations, that in turil are necessary for attributing mental states to both themselves and other people (Baron-Conen et ai.., 1985; Premack \& Woodruff, 1978). This means they are unable to 'put themselves in sonieone else's shoes' and imagine their thoughts and feelings; something that is necessary if we are to explain and predict other people's behaviour (Baron-Cohen, 2008; Astington, 1994; Lewis d Mitchell, 2014).

The cognitive capacity for 'meta-representation' is said to underise the psychological functions of pretend play as well as the understanding of other people's mental states, as both require the 'decoupling' of mental representations from 'reality' As what another person may think, believe or say, does not always correspond to reality, it is proposed that the child needs to be able to decouple his or her representation of what the other person believes from the true state of affairs by forming a metarepresentation of the first-order representation of the belief (Leslie, 1987). The capacity for pretend play is said to rely upon two psychological functions: the ability to treat an object as if it were something else (for example, a stoe as though it were a boat), and the appreciation that an object is not really the same as the thing it represents (Leslie, 1987). This account of autism regards symbolism as dependant on a decontextualized cognitive capacity, and largely disregards the constraining and enabling functions of the object itself. Several recent studies have shown, however, that the object, far from being incidental, is an essential component of the representational act. Children are acutely senisitive to what any particular object could be used to represent and to the actions it affords, being happy to pretend that a shoe is a boat, for example, but emphatically refusing to use a comb in the same way (Bugrimenko \& Smirnova, 1992; Szokolsky, 2006).

Whilst proponents of 'Theory of Mind' have relatively little to say about object use in autism, the logic of this position predicts a clear pattern of disruption, such that activities requiring the ability to 
meta-represent, like pretend play, would be impaired, whilst those not underpinned by this cognitive capacity ought to remain unaffected. This is clearly illustrated by the rigid distinction drawn between 'functional' or 'reality' play on the one hand and 'pretend play', on the other, arguing that the former is intact in autism whilst the latter is impaired (Leslie, 1987). Leslie (1987) argues that functional play with real objects or miniature versions of everyday objects, such as pushing a toy car along the ground, or putting a spoon to the mouth of a doll (relating two associated objects together) simply demonsirate a conventional understanding of objects involving only a first-order representation. However, a review of evidence relating to object use and autism is not consistent with such a position, with disruntion extending well beyond pretend play, to include early exploratory and functional play, as well as the conventional use of human artefacts in everyday routines ${ }^{1}$.

\section{Object interactions of children with ASD}

Research findings suggest that children with, or at high risk for, A.SD differ markedly in their engagement with objects in both play and everyday settings compared to TD children and those with other developmental difficulties (Rowland \& Schweigert, 2009; Wilson et al, 2017; Williams, 2003).

Object play. The early solitary object exploration of young children with ASD, which involves simple, indiscriminate, manipulations (e.g. banging, waving mouthing) of objects to extract information about their sensory and motor properties, is characterised by a number of unusual features inconsistent with developmental age (Willians, 2905; Naber et al., 2008; Wilson et al., 2017). Children with ASD appear to persist in this type or early indiscriminate manipulation of objects for longer than developmentally matched controls (Blanc et al, 2005; Sigman \& Ungerer, 1984; Libby, Powell, Messer \& Jordan.1993; Wilssn et al., 2017). They also show a greater preference than children in comparison groups for exploying objects using the proximal senses of touch, taste and smell rather than vision, along with a tendency to become preoccupied with parts of objects and to use them stereotypically such as iining them up in rows and on top of each other (Williams, Costall \& Reddy, 1999; Williams, 2003). In addition, their visual inspection of objects can take an odd form, where objects are twisted close to their eyes, or just one object or a single part of it is looked at for extended periods of

\footnotetext{
${ }^{1}$ Whilst Baron-Cohen's (2008) more recent development of the 'Theory of Mind' model, his two-factor empathisingsystematising hypothesis, can better account for some unusual uses of objects by children with autism, it does so at the expense of reinforcing even more strongly the notion of a rigid divide between the social and non-social world, with individuals with autism experiencing significant problems in the former whilst showing considerable strengths in the latter.
} 
time (Freeman et al, 1979; Ozonoff et al., 2008; Williams, 2003). Compared to controls, high-risk infant siblings of children with ASD have difficulty disengaging attention from objects (Sacrey, Bryson \& Zwaigenbaum, 2013) and show more repetitive actions on objects (Elison et al., 2014). Both qualitative and quantitative differences have been found between young children with ASD and developmentally matched controls in studies of functional play. Although children with autism do engage in this type of play, evidence suggests that they do so less frequently than TD children and those with other learning difficulties, at least in unstructured situations, tending instead to produce nore stereotypical, self-stimulatory or non-functional actions on objects (Wilson et al., 201\%; Vy 1liams et al., 1999). Furthermore, the functional play they do produce is less elaborated, varied and integrated than that of children in matched comparison groups (Williams, Costall \& Reddy, 2001).

Use of everyday objects. Evidence from case studies (Asperger, 1944-Park, 1983) and from two comparative studies that investigate the acquisition of everyday object use by young children with autism suggest that parents of these children experience greater difficulties than those of non-autistic children in introducing them to the culturally specific use of various everyday objects (Williams, Kendell-Scott and Costall, 2005) and that their chirdren's acquisition of these conventional uses is considerably delayed (Rowland \& Schweigert, 2009). Parents of children with autism report the failure of their child to copy other people's actions on objects, their refusal to eat at the meal table with other family members (thereby lixniting the possibility of learning through observation) and the necessity for repeated verbal promsting, demonstration or hand-over hand physical guidance before an appropriate response can be elicited (Asperger, 1944; Park, 1983; Williams et al., 2005). Furthermore, only parents who had children with ASD reported that their child's odd use of certain objects, or interest in isolated aspects of an object, interfered with attempts to get the chila to use an object in an appropriate way (Williams et. al, 2005).

\section{Afíordances and object use in autism}

Amongst recent theorists, Loveland (1991) is alone in emphasising widespread difficulties in how children with ASD deal with objects. She draws upon Gibson's (1979) concept of affordances to develop a theoretical alternative to representationalist accounts of autism. The theory of affordances attempts to put meaning back in the world, first by relating it to action, “... to see things is to see how to 
get about among them and what to do or not do with them" Gibson (1979, p.223), then by addressing the neglected mutuality of agent and world. Gibson proposed that what we primarily attend to in our surroundings are not isolated properties such as shapes and edges, but rather 'affordances', the opportunities things offer (afford) for perception and action relative to the specific physical and psychological capacities or effectivities of a particular organism: "The affordances of the environment. are what it offers the animal, what it provides or furnishes, either for good or ill...It implies the complementarity of the animal and the environment" Gibson $(1979, \mathrm{p} .127)$. The relationship between organism and environment is seen as a mutual one, with each developing in relation to the other.

Loveland (1991) identifies three kinds of non-exclusive affordances in the child's environment: the 'physical', the 'culturally selected' and the 'social and communicative' She argues that autism involves a specific impairment in the child's ability to detect not only the afforidances of other people, but the culturally selected affordances of things. Loveland (1991) discusses many aspects of object use, in contrast with the 'Theory of Mind' approach, including the appropriate use of objects, and we share her view that Gibson's concept of affordances provides a usefuil framework for considering the problems that children with autism have with obiects. One of the reasons object use has been neglected in popular theoretical accounts of autisn has been their overriding concern with the development of hypothetical 'internal' cognitive structures and most recently the neural connections in the brain involved in these mental processes. Gioson's concept of affordances brings objects back onto the agenda by bridging the gap between activity and its material conditions. However, whilst Loveland (1991) discusses the importance of social referencing and joint attention and claims that the different kinds of affordances ate not mutually exclusive, she stops short of elaborating upon the developmental interplay between the child's understanding of the culturally selected affordances of objects and the socia! and communicative affordances of other people. Her account, perhaps unintentionally, seems to invoke the questionable assumption that, in so far as any child with autism can cope with objects, this basic level of understanding is asocial. This perhaps reflects the problem that the concept of affordances, as widely understood, has had with failing to fully appreciate the sociality of the material (Costall, 1995). Gibson, in his overriding concern to get away from the idea of mediation by internal representations and language in order to focus on the material conditions of action, proved ambivalent 
about pursuing the implications of the fact that we develop and live in a sociocultural milieu (Costall, 1995; 2012).

\section{The interpenetration of the social and material}

Bodies of research and theory within developmental psychology broadly guided by the sociocultural (Valsiner, 1987; Leontiev, 1981; Tomasello, 1999) and ecological (Costall, 2012; Costall and Dreier, 2006; Preston, 2000; Szokolszky, 2006; Williams \& Costall, 2000; Williams et al., 2005; van Leewwer, Smitson \& van Leeuwen,1994; van Leeuwen \& Westwood, 2010) frameworks challenge the assumption of a rigid separation between the social and the material in children's developing understanding and use of objects. Proponents of these approaches contend that assuming such a dualism: 1) fails to recognise the far-reaching impact that commonplace artefacts (such as eating utensils) can have in shaping everyday human practices in common ways, and 2) ignores the fact that we encounter objects

in a social context and other people play a key role in introducing children to, and guiding directly and indirectly, their 'proper' use.

One important aspect of the child's develoning sense of the meaning of things is their learning to appreciate that most of the everyday objects they eñcounter have a single, definite, function or 'canonical affordance'; the 'widely accepted use-meaning' of a thing (Costall, 2012, p. 92). Contrary to James Gibson's (1979) clairns or continuity between 'affordances in general' and the 'canonical affordances' attached primarily to human artefacts, Costall (2012) argues that the latter are crucially distinguished from the former by their normative, conventional and objectified status. For example, a cup remains an object for drinking out of, even when it resides unused in a cupboard or is co-opted temporarily for another use, such as storing small items. Its use-meaning resides not at the level of the object itself or individual-object dyad, but in the context of a wider social network involving other people, related objects and shared cultural practices. These cultural practices both incorporate and are themselves shaped by particular human artefacts, as well as having the potential to change their normative use (Costall, 2012). Everyday objects such as a toothbrush, toothpaste, flannel and soap provide a means by which the child enters into the common (in this case grooming) practices of society (Volpert, 1985). Preston (2000) argues that appropriate eating behaviour at the table is organised 
systematically with regard to the proper functions of the tableware: "Take cutlery in Western culture. Forks, spoons and knives have a specific set of eating functions that are proper to them, and these functions govern the behaviour we call table manners" (p.41). We argue that Loveland's (1991) concept of 'preferred affordances', which she uses to refer to culturally determined affordances reflecting preferred but not necessary interaction, does not really capture the institutionalised, normative status of canonical affordances (Costall, 2012; Williams \& Costall, 2000).

Infants and children are not typically left alone to discover their own use-meaning for an obiect. This is not just a matter of preventing them from investigating things that could endariger then such as electric plug sockets) or that they themselves could damage (such as china ornamenis). Rather, they are introduced by more experienced others to the intended function of particuiar artefacts:

[The] notion of an individual, a child, who is all by itself with the world of objects, is a completely artificial abstraction. The individual is not simpiy thrown into the human world; it is introduced into this world by the people around it; and they guide it in that world (Leontiev, 1981, p.135).

According to Valsiner (1987), a number of factors converge to ensure the cultural canalisation of infants' use of everyday artefacts: direct and inairect guidance by caregivers (and older siblings), the child's own eagerness to participate in the activities of the adults around them, and the nature of the object itself. Valsiner carried out a snail number of longitudinal case studies in which every 2-3 months from the age of 7 or 8 months to 2 years he videotaped mothers and their infants interacting during mealtimes. Mothers were observed to use a number of different techniques aimed at channelling their child's atiention and skill in using the implements they were given in culturally appropriate ways, including structuring the wider setting so as to promote desired actions whilst discouraging undesirable ones. For example, in teaching their child to use a spoon or fork correctly, the parent usually placed the infant in a high-chair, restricting their freedom of movement, and moved distracting objects out of the way. Only then was the cutlery presented, at the appropriate orientation, to the child. Brief and intermittent periods of joint action tended to occur in the early stages of an infant learning to use a particular implement. Either the mother placed her hands over those of the child, who was holding the object, and physically guided their action, or they performed a sub-part of an action, such as loading a 
spoon or fork, leaving the child to do the rest. As the children became more adept at using the cutlery, the mothers were more likely either to verbally prompt the child, if they became distracted for example, or to praise the correct use of an item of cutlery. Valsiner (1987) proposed that only short and occasional periods of intensive instruction by the parent are usually required, as the child's interest in other people's activity and their willingness to copy them ensures that their actions will, eventually, be canalised even without direct intervention.

The child's eating behaviour is not only shaped through direct and indirect guidance by the more culturally experienced people around them, but also through the very form of the artefacts commonly used at mealtimes (Leontiev, 1981; Valsiner, 1987; Preston, 2000; Williams \& Costall, 2000). According to Valsiner (1987), the cultural canalisation of childrer" sactions starts from "the coding of some suggestive cultural messages into the form and function of gijects" themselves (p.173). Objects intended specifically for children are not simply scalea dewn veisions of those used by adults, but are often specifically constructed to further constrain and guide the infant's activity. For example curved cutlery, 'Anywayup' beakers, and 'Doydy' cups, whose lip is slanted in such a way as to require less tipping by the child to get the liquid into he miduth.

\section{Triadic play and the mutuality of the social and material}

Given evidence of the interpenetration of the social and material, it would seem reasonable to suppose that children who have trouble relating to other people would also have extensive difficulties entering into the appropriate use of cultural artefacts, not only in the context of everyday routines like washing and eating, but also in their play with other people, with significant developmental consequences. It is also possible that any unusual uses of objects will itself disrupt such triadic interactions. From around the second half of the first year children begin to enter into joint objectcentred engagements involving both the child's co-ordination of attention between objects and other people along with the sharing of activity surrounding those objects (Bakeman \& Adamson, 1984; Brooks \& Meltzoff, 2002; Vaughan Van Hecke et al., 2007). Parent-child interactions centred on objects are widely presumed to be an important precursor to communicative and linguistic development (Bakeman \& Adamson, 1984; Lieberman \& Yoder, 2012; McArthur \& Adamson, 1996). According to Bruner $(1975 ; 1982)$ the predictable communicative formats, such as turn-taking, that emerge between 
the infant and caregiver during such play structurally underpin many features of language. As the social, normative, conventions surrounding object use are based on "mutual expectations, accepted usage and uniform standards" (Turiel, 1978, p. 26), they too constitute part of the predictable framework around which other skills can be built; providing a focus of common interest and helping to structure the interaction in standard ways. Much triadic play between parents and their children involves toys that are designed to invite imitation of practices in the adult world, such as cookers and tea sets. Indeed, the extent to which they prescribe actions and meanings has been criticised as inhibiting the child's creativity:

Faced with this world of faithful and complicated objects, the child can only identify himself as owner, as user, never as creator; he does not invent the world, he uses it

(Barthes (2009/1972, p39; Cited in van Leeuwen \& Westwood, 2010). However, as van Leeuwen and Westwood (2010) point out, sueh toys perform an important role in communicating the cultural contexts of objects and actions, as veli as in shaping and supporting parentchild interactions. In a recent study Palacios and Rodrígue (2015) present compelling evidence suggesting that children's symbolic (pretend) play is 1tself strongly grounded in these predictable conventional uses and actions with toys'objects in the context of triadic play. Only once these conventional uses and actions are established do first parents, and then their infants, begin to use these objects more symbolically. In other sords, symbolic use is said to rely on a material reality that is already routinely regulated, rather than disembodied and hypothetical internal cognitive mechanisms.

As discussed above in addition to providing a bridge to the development of essential skills relating to language, commınication and social interaction, it has been proposed that interactions with caregivers involving objects, serve to mediate the infant's appropriation of the social conventions surrounding object use (Loveland, 1991; Rocissano, 1982; Williams et al., 1999). To provide evidence for the social hecaiation of object use, Rocissano (1982) videotaped infants at 22, 24 and 26 months engaging in freeplay with a parent and a set of traditional toys. Amongst other behaviours, she recorded the number of conventional acts produced by the children that did not depend on the initiation of their parent, and that were not supported by the nature of the object itself (in the case of a ball, for example, simple exploration could lead to the accepted usage, whereas stirring a spoon around in a pot is much less likely to be arrived 
at without social support). Rocissano (1982) found that these conventional acts increased in frequency and variety with infant age. She contends that, as the actions were unsupported by the immediate context, the only way the children could have initially acquired them is through past observation of someone else performing a similar action with a similar object. The same pattern of an increase in conventional actions with age was identified regardless of whether the toys were specifically designed to represent the real world or not. The finding that actions on replica objects also grew increasingly conventional with age offers further support for the proposition that other people play a role in shaping infants' use cf cbjects, as it suggests that however socially relevant the object itself, it is not on its own sufficient 10 wholly support the production of conventional actions.

Autism, object use and joint engagement. Given the proposed foundational importance of joint object-centred interaction in the social conventions surrounding object wse, communication, language and social interaction, it is clearly a matter of concern when childiren are known to experience difficulties entering into such engagements, as evidence suggests is the case for children on the autism spectrum (Lieberman \& Yoder, 2012). Extensive researcli tas been conducted in the field of autism on deficits in alternating gaze between a person and a toy (Bruinsma, Koegal \& Koegal, 2004) and on the rare use of joint attention gestures inviting giner people to share their exploration of an object (Mundy, Sigman, Ungerer \& Sherman, 1986; 1987: Mundy, Sigman \& Kasari, 1990; Baron-Cohen, 1989a, 1989b; Baron-Cohen, Allen \& Gillberg, 1992) However, in spite of the fact that several researchers have drawn attention to the difficyities that children with ASD appear to have in using objects in normal ways (Bachevalier, 1094; Leveland, 1991; Williams et al., 1999; Williams et al, 2001; Wilson et al, 2017) very little attention has been paid to the problems there may be in establishing the object as an items of shared interest and the repercussions this may have on the child's ability to enter into and sustain joint engagemerits centred on objects. Unusual explorations of objects such as bringing them close to the eyes for inspection (Wing, 1969; Hermelin \& O’Connor, 1970; Ozonoff et al., 2008), focussing on a single part for an extended period of time (Gillberg et al., 1990) or difficulty disengaging from an object (Sacrey, Bryson \& Zwaigenbaum, 2013) may serve to preclude the sharing of an object with another person, or at the very least, disrupt the reciprocal processes that usually operate between the child, caregiver and object. 
Both Lewy and Dawson (1992) and McArthur and Adamson (1996) found that the way attention was distributed between an adult partner and/or objects during episodes of joint engagement distinguished children with autism from developmentally matched comparison groups. In both studies the children with autism spent relatively more time focussing on an object to the exclusion of the adult and, conversely, less time alternating their attention between an object and their partner. More recently, Bruckner Taylor \& Yoder (2007) found that in a semi-structured play situation young children with ASD who demonstrated more restricted object use (less diversity in number of toys played with and differentiated actions performed on them) were less aware of adult (researcher) directives, prompts and demonstrations. The researchers suggest that the narrow focus ('attentional spotlight') indicated by restricted object use may prevent the children using their 'attentional searchlight' to pick out available attentional cues in the environment. These findings raise the question of whether the child's apparentily greater tendency to engage with an object to the exclusion of their adult partner itself plays a

part in disrupting the mutual processes that usually function between caregiver, child and object.

\section{Current study}

Given evidence of the mutuality of the social and material, children with autism should face two inter-related problems. On the one hand ineir difficulties in engaging in joint object-centred play with other people means that their opportunities for learning about the conventions surrounding object use are severely restricted. On the other, their tendency to use objects in idiosyncratic ways may make it difficult to establish and miaintair joint engagement with someone else. The study presented sought to clarify these issues through observing children with ASD, children with Down syndrome (DS) and typically deveioping (TD) children playing with a parent and set of conventional toys.

The secial mediation of object use. A drawback of most previous research examining joint engagemerit processes centred around objects, is that it has tended to focus exclusively on the child's actions. This means that the role played by other people in mediating the conventional use of objects can only be inferred indirectly. In the present study we recorded the behaviour of both parent and child. We focussed initially on the parent, in order to determine in what ways they introduced objects to their children and the relative frequency with which this comprised an invitation to act on an object in a particular way. Following each parental invitation the children's responses with regard to their level of 
interest in, or compliance with, the initiating invitation were coded. We hypothesised that, relative to developmentally matched controls, dyads involving a child with ASD would be characterised by a proportionately lower number of child responses showing evidence of interest in invitations made by parents. We also hypothesised that, as a result of this disrupted pattern of interaction, parents of children with ASD would make relatively fewer attempts to shape their child's action on an object. In addition to these event-based observations, we defined a number of mutually exclusive "engagement states" describing the nature of the child's involvement with objects and/or their parent. We preáicted that, unlike children in the comparison groups, those with ASD would spend more of their total playtime in 'non-interactive' states, in which there is no sharing of an object between the child and parent.

Preoccupation with own object use. We also examined the types of responses the children made to their parent's invitations to act on/attend to an object, to investigate whether preoccupation with their own uses of objects by children with ASD would disrupt sharing of an object with their parent to a greater extent than developmentally matched controls. In adidition, we assessed the proportion of total playtime spent engaged exclusively with an coject. We predicted that the children in the ASD group, given their difficulties engaging with other people and evidence of their idiosyncratic relations with objects, would be more likely to fai to respond to their parent's invitation to engage with an object as a result of being absorbed in their ewn act with an object and would also spend proportionately more time engaged exclusively with an objest, relative to controls. We also hypothesised that, again as a consequence of their unusual use of objects, the nature of the actions produced by the children with ASD categorisea as own acts with an object', would be more likely to preclude interaction with a caregiver than those acts produced by children in the comparison groups coded in the same category.

\section{Method}

\section{Farticipants}

Thirty-six children, aged from 1 to 6 years of age ( $M=42.8$ months, $S D=15.1$ months), participated in the study along with their primary caregivers: 12 typically developing children (TD), 12 children with autism (ASD) and 12 children with Down syndrome (DS). The primary caregivers were all mothers, except in the case of one girl with ASD and two boys with DS where the 
father was the main carer. The dyads were drawn from a data pool of 45 families who took part in a larger study designed to investigate person-directed play (Reddy, Williams \& Vaughan, 2002). The sample of TD children was recruited through family doctors. A letter was sent out from the doctor's clinics to parents of suitably aged infants requesting volunteers for the study. The children with ASD were selected by approaching professional diagnostic clinics in the South of England. Each child had received a formal diagnosis of autism according to the criteria given in either the International Classification of Diseases, 10thedition (ICD-10, World Health Organisation (WHO], 1990) or the Diagnostic and Statistical Manual IV (DSM-IV, rev., American Psyehiatric Association [APA], 1994), respectively. They also all scored 32 or more on the Childizood Autism Rating Scale (CARS; Schopler, Reichler, \& Renner, 1986), completed inciepenciently by a trained clinical psychology assistant. The children with DS were recruited using the data base held at the Sarah Duffen Centre (Portsmouth Down Syndrome Trust) based at the Jniversity of Portsmouth.

\section{Table 1 about here}

The groups of children were matched for general developmental age using the second edition of the Bayley Scales of infant Development (BSID II; Bayley, 1993). The DS and ASD groups were also matched as closely as possible for gender and chronological age, as it was thought that both factors could infiuence he children's experience with the toys (see Table 1). In addition, all the groups were assessed for receptive language. Those children whose language age was thought to be below 16 months ( $n=6$ in each group) were assessed using the MacArthur Communicaitve Inventory (Fenson et al., 1993). The receptive language ages of the other chidrein ( $n=6$ in each group) were obtained using the receptive sub-domain of the Virelarid Adaptive Behaviour Scales (Sparrow, Balla \& Cicchetti, 1984). In both these psychoinetric tests information is gained from a parent regarding their child's language ability. A Gne-way ANOVA revealed no significant group differences in receptive language scores, $F(2,33)=$ $0.56, p=0.58, \mathrm{~ns}$.

\section{Procedure}

A home visit, lasting approximately 2 hours, was made to each family. The child was first sat in the middle of the floor and presented with a set of novel toys that were arranged around them 
in random order. They were left to play with these on their own for 15 minutes. This allowed them to familiarise themselves with both the toys and the presence of the investigator in their home.

During this time the parent was asked not to demonstrate any play behaviours with the toys and to avoid interacting with their child, other than to comfort or protect them if required. The same toys were presented to each child who participated in the study and included a tea-set, doll, doll bathtub, small cloth (12 x 8 inches), toy hairbrush, baby bottle, cooking equipment, hand and finger puppets, watering-can, toy cars, dustpan and brush, toy telephone, a small plastic box, rattle, music box and a ball (see Figure 1). Sessions took place in a room of the parent's choice, typically a front room or playroom. Following familiarisation, the parent was asked to join their child on the floor and engage them with the toys 'doing what you normally would do'. The chile was vidcotaped interacting with their parent for a total of 10 minutes, using a camcorder. Videotaping was continuous, unless the child wandered out of the view of the caniera, er became disengaged with the parent and/or objects for longer than 30 seconds. Whet this happened the experimenter asked the parent to try and attract their child's attention back to the objects as soon as possible.

Videotaping was resumed when the child became re-engaged with the toys and/or their caregiver. Following the play session the same experimenter administered the baseline psychometric tests. The session was stepped if, at any time, the child became too upset to continue, or if repeated atternpts to attract them to the toys were not successful. In such cases the investigator retrirned for a second visit within two weeks.

Figure 1 here

\section{Coding Procedure}

Event Coding. An event-based coding scheme was used to record the occurrences of parent Initiations involving the toys. Coders focussed on the caregiver and coded an event whenever they initiated behaviours or verbalisations that invited their child to act on or share attention to a particular toy/object. These parental invitations were grouped into three main categories, each of which was further divided into two sub-categories (see Table 2). The first main category, invitations to act on an object, consisted of parents' attempts to direct their child's action on an object, either by verbally suggesting a particular action or physically demonstrating a particular act 
themselves. We decided not to further sub-categorise this type of parent invitation into those that invited the child to act conventionally versus those that did not, as a preliminary analysis revealed that over $90 \%$ in all groups were conventional. The second category, invitations to share attention to an object, were defined as calling their child's attention to an object, or new aspect of an object with which the child was not already engaged, using conventional 'markers' such as, pointing or words to refer to the object. In contrast, the third category, invitations that physically elicit attention to, or action on, an object, included those cases where a parent gets their child to attend to, or act on, an object by: physically guiding the child's object use (hand over hand); actually torohing the child with an object or manipulating an object in such a way as to make it perceptually more salient to the child (e.g. shaking a rattle by the child's ear). The coders noted the category and exact time of onset of the parent's invitation and recorded it verbatim.

The child's responses to these initiating events were alse coded and described verbatim. These were divided into two main groups, responses showing interest in the parent's invitation and those where no interest in the invitation was apparent. Each of these categories was divided into three subcategories (see Table 2). The rationale for dividing the children's responses in this way was to distinguish between those responses that would prevent the sharing of an object between the child and caregiver (reject, ignorelown act own act with an object) from those that would allow such a sharing to take place and where the caregiver would be able to impart information about an object or objects to their child (look, comply, elaborate). Given research evidence regarding certain unusual relations with objects found in children with autism (Williams et al, 1999; Wilson et al., 2017), and our contention that such relations would actually function to block interaction with another perssin, we decided to further sub-divide behaviours recorded in the category 'own act with an object' according to whether they would preclude interaction with the parent (preclusive), or not (non preclusive). Under 'preclusive' we included acts such as very close inspection of an object, or extended absorption in a single part of an object, that we thought would make it very difficult for a parent to engage their child with another object (see Table 2). 
State Coding. A state-based coding scheme was used to assess how each child deployed their attention and/or activity during the parent-child play session. This was based on the Engagement State Coding Scheme developed by Bakeman and Adamson (1984) and revised for use with developmentally delayed infants by Girolametto, Verbey and Tannock (1994). Eight mutually exclusive "engagement states" (including unclear) were defined, that characterised the child's involvement with objects and/or their parent (see Table 3). The coder's task was to 'segment' the stream of behaviour shown in the triadic play sessions into sequences of these states, in order to identify whether the child was engaged exclusively with an object $\left(\sigma_{j}\right.$ ject $)$, exclusively with their parent (person), with neither object or parent (unengaged), or with both an object and their parent (onlooking, elicited, supported, co-ordinated). Four separate categories covered cases where the child was focussed on their parent and an object, to capture the degree of involvement and extent of the child's co-ordination between their caregiver and the shared object (see Table 3). Coders played a tape in real time untii they decided that the current engagement state had changed. They then reversed the tape, positioning it before the suspected change in engagement state, and played it again forward in real time, stopping the tape at the break point and recording the particular state onset cime Brief fluctuations in attention of less than 2 seconds were not coded as periods of attention or engagement are viewed as states having a certain duration (Bakeman \& Adamson, 1984).

Table 3 about here

It yas not possible to code a full 10 minutes (600 seconds) of play for every parent-child dyad, as several children in each group lost interest before this time had elapsed. The overall mean number of analysable seconds of dyadic play obtained for each group were: 538 (TD), 541 (ASD) and 509 (DS). A One-way ANOVA confirmed that there were no significant differences between the groups. Coding was done using an editing VCR (Panasonic AG 7355B) and an 11-inch monitor.

\section{Interobserver Agreement}

Interobserver agreement was assessed by having a trained graduate student code 3 tapes, randomly selected, from each of the groups of children. This amounted to about $25 \%$ of the corpus. The 
student was blind to the purpose of the study and had no prior dealings with the participants. They were previously trained in the coding procedure using six tapes; two from each of the groups. Interobserver agreement coding was begun once a satisfactory overall percentage agreement of $70 \%$ or more was reached during training, between the graduate coder and the first author (who coded all the variables on every children). The resulting Cohen's Kappa's were all within acceptable limits (Cohen, 1960). Those for the 8 engagement states (including unclear) ranged from $0.78-0.90$ (89-97\%), with a mean of (1.83 (94\%). Kappa's for the 6 sub-categories of parent invitations and the 7 sub-categories of child response, including preclusive versus non-preclusive (see Table 2) ranged from $0.85-0.87(95.99 \%$ ) and 0.70 $0.87(84-97 \%)$, with means of $0.86(95 \%)$ and $0.76(88 \%)$ respectively.

\section{Results}

\section{Parent Invitations}

The data were examined first to see if any group differences existed in either the total number or type of invitations parents made to their children. A one-way ANOVA indicated that no reliable group differences with regard to the totai numbe: or parent invitations, $F(2,33)=1.63$, ns. However, differences were found in the kinds of in vlations made. These were computed by dividing the frequency of parent invitations made in each main category, by the total number of invitations recorded for each parent to give the proportion of each type, as we were interested in the relative proportion of in itations inade in each category. Exploratory data analysis identified that the assumptions of normality and homogeneity of variance between groups were met for parent invitations to act en an object and to share attention to an object, but not for those that physicaly yelicited their child's attention to/action on an object. Parametric statistics were therefere used to examine group differences in the first two types of invitation and non-parametric statistics to investigate the latter (Field, 2009).

A one-way ANOVA found reliable group differences for invitations to act on an object, $F(2,33)=4.53, p=.018$, but not for invitations to share an object, $F(2,33)=2.12$, ns. Post-hoc Tukey-HSD tests indicated that parents of children with ASD made proportionately fewer invitations to their child to act on an object than either parents of children with DS $(p<.01)$ or TD children $(p<.05)$. In contrast, no differences were found in this regard between the control 
groups (see Figure 2). One-way ANOVA's comparing the sub-categories of invitations to act on an object, suggest and demonstrate, indicated significant group differences in both variables $($ suggest: $F(2,33)=5.63, p<.01$; demonstrate: $F(2,33)=4.3, p=.05)$. Post-hoc Tukey-HSD tests indicated that the source of these differences lay primarily in the proportionately fewer verbal suggestions to act on an object made by parents of children with ASD, compared to parents of children with DS $(p<.01)$. Parents of children with DS were also proportionately less likely to demonstrate the use of an object than those of TD children $(p<.05)$. Despite these differences, however, invitations to act on an object in all groups were proportionately the mosc frequentily observed type of parent invitation, comprising more than three-quarters of the totai in DS (.77) and TD (.79) and nearly two-thirds in the ASD group(.62).

Figure 2 about here

A Kruskal-Wallis one-way ANOVA identified significant differences between the three groups in the proportion of total parent invitations categorised as physically elicited, $\chi^{2}(2)=9.9, p<.01$. Mann-Whitney $U$ tests showed that the parents of children with ASD were more proportionately more likely than those with DS to initiate invitations that physically elicited attention to, or action on, an object, $U=18.5, p<.005$. There was a so a trend for parents of children with ASD to produce proportionately more invitations in this category compared to those with TD children, $U=41.0$, $p=.07$. The sub-categories, $p$ hysicaily structure and physically elicit attention, were not analysed separately, due to the smali overall number of these kind of invitations recorded.

\section{Child responses to parent invitations}

To ciscern whether children in the different groups responded differently to their parent's invitations the proportion of total responses recorded for each child response category (see Table 2) was examined as a product of the main category of parent invitation that evoked it. The responses were analysed in relation to the category of invitations that evoked them in recognition of the fact that these are not independent of each other (see Table 4). The frequency of responses in each child response category were divided by the total number of responses made to each category of parent invitation. Non-parametric statistics were then used to investigate group 
differences as the data violated the assumptions of homogeneity of variance and normality.

Child response to invitations to act on an object. A Kruskal-Wallis one-way ANOVA revealed significant group differences in the following child response categories: own act, $\chi^{2}(2)=10.58, p<.005$; own object, $\chi^{2}(2)=14.41, p<.001$; comply, $\chi^{2}(2)=20.65, p<.001$; and elaborate, $\chi^{2}(2)=7.30, p<.05$. The children with ASD were proportionately more likely than either of the controls to disregard their parent's invitation to act on an object, either due to being preoccupied with their own particular use of an object (DS: $U=16.5, p<.001$; TD: $U=16.0, \mathrm{p}<.001$ ) or absorbed in their own non-object centred action (DS: $U=11.0, p<.05$; TD: $U=29.0, p<.05$ ). Conversely, they were proportionately less likely to react to their parent's invitation by complyirg, or elaborating on it, relative to both children with DS (comply: $U=11.0, \mathrm{p}<.001$; elaborate: $U=35.5 .0<.05$ ) and TD children (comply: $U=5.0, p<.001$; elaborate: $U=37.0, p<.05$ ). No differences were found between the TD and DS groups with regard to any response category (see Figure 3).

Figure 3 about here

Child response to invitations to share ateention to an object. Analyses suggested that the pattern of findings for the children's responses to invitations to share attention to an object was similar to that identified for their responses to parental invitations to act on an object. The categories comply and elaborate yere amalgamated for all analyses as very few children in any group elaborated on this type of invitation by acting on the object(s) to which their attention had been drawn so as to invoive their parent in a new act or extend an already established game/scheme. One-way Kruskal-Wallis ANOVA's found significant group differences in: own act on object, $\chi^{2}(2)=9.03, p<.01$; comply/elaborate, $\chi^{2}(2)=15.12, \mathrm{p}<.001$ and; ignore/own act, $\chi^{2}$ $(2)=6.45, p<.05$ Mann-Whitney $U$ tests indicated that the children with ASD were propertionately more likely ignore their parent's invitation as a result of being preoccupied with an. object, relative to the TD, but not children with DS (TD: $U=24.5, p<.005$ ). They were also proportionately less likely than DS, but not TD children, to comply and/or elaborate on this type of parent invitation (DS: $U=32.0, p<.05)$.

Child response to invitations physically eliciting attention to/action on an object. KruskalWallis one-way ANOVA tests found significant group differences in the categories: own act on object, 
$\chi^{2}(2)=12.04, p<.005$ and reject, $\chi^{2}(2)=6.34, p<.05$. Mann Whitney $U$ tests showed that children with ASD were proportionately more likely to reject their parent's attempt to physically elicit attention to, or act on, an object compared to those with DS, $U=42.0, \mathrm{p}<.05$ and TD children, $U=45.5, p=.07$, with the latter indicating a trend rather than significant difference. They were also proportionately more likely than both control groups to be preoccupied with their own use of an object when their parent attempted to physically elicit their attention to/action on an object (DS: $U=30.0, p<.005$; TD: $U=37.5, p<.05)$.

Table 4 about here

Preclusive versus non-preclusive 'own acts with objects'. A further aralysis of at the child responses coded in the sub-category 'own act with an object' was then undertaken with respect to whether or not they precluded parental involvement. A Kruskal-Wallis test found significant group differences between the autism and control groups, $\chi^{2}(2)=19.65, x<001$ Of all the 'own acts with an object' recorded for the children with autism, an average proportion of .45 were categorised as preclusive (i.e. as involving the very close inspection of an object, absorption in isolated properties, or extended interest in a single part of an object), compared to only .03 and .06 of those responses recorded for the Down and typical children, respectively. Mann Whitney $U$ tests showed these differences to be high!y significant (DS: $U=12.5, p=.001$; TD: $U=10, p<.001$ ).

\section{Engagement States}

Kruskal-Wallis one-way ANOVA tests were computed to identify if any group differences existed in the childron's allocation of attention/action during the play session (see Figure 4). Significant group differences were found in the following engagement states: object: $\chi^{2}(2)=9.37, p<.01$; unengaged: $\chi^{2}(2)=12.28, \mathrm{p}<.005$; co-ordinated: $\chi^{2}(2)=14.95, \mathrm{p}<.001$; elicited: $\chi^{2}(2)=3.71, \mathrm{p}<.001$; person: $\chi^{2}(2)=7.84, p<.05$. Caution needs to be taken with the latter two findings, however, as very itite time was spent by any child either focussing exclusively on their parent or where their attention was involuntary. Further analyses were not, therefore, conducted on these data. MannWhitney $U$ tests indicated that the ASD group spent a greater proportion of the parent-child play session focussed on their own use of an object, to the exclusion of their caregiver, relative to both sets of controls (DS: $U=28.5, p<.01$; TD $U=26, p<.01$ ). They also spent proportionately more time than 
both DS and TD children unengaged with either an object or parent (DS: $U=21.5, p<.005$; TD:

$U=18.5, p<.005)$. Conversely, they spent proportionately less time than controls in co-ordinated joint engagement, actively co-ordinating their attention/action between an object and parent (DS: $U=17, p<.001$; TD: $U=12, p<.001)$.

Figure 4 about here

In order to examine group differences in engagement states a 3 (group: DS/ASD/TD) x 2 (engagement state: interactive/non-interactive) ANOVA, with repeated measures on the latier variable was conducted. The interactive variable is a sum of the time spent by the child in states that clearly involved a sharing of an object, or set of objects, between the child and their parent (i.e. the categories of co-ordinated and supported).

In contrast, the non-interactive variable was a sum of those states where it was clear that no social mediation of object use could take place between the two partrers of the dyad (i.e. object, unengaged; and person). This means that not all the engagenient state behaviours coded were included in this analysis. Time spent in the elicied state was not included, as although it could be argued that some sharing of the object is taking place between the child and parent, the child's attention is not voluntary. In adiition, time spent onlooking was not coded as interactive as it was not always clear from the videotape analysis whether the child was taking in information about what the parent was doing, or simply looking 'absently' in the parent's direction. A significant main effect for engagement state, $F(\mathrm{I}, 33)=29.59, p<.001$, was identified, suggesting that overall the children spent a greater proportion of their time in states where an object vas being shared, rather than those where no sharing was taking place.

A significant interaction effect between group and type of child response, $F(2,33)=26.56$, $p<.001)$, was also found. Tukey-HSD tests indicated that the children with autism spent a greater pioportion of their total play time in non-interactive engagement states, compared to both Down $(p<.001)$ and typical children $(p<.001)$. Correspondingly, they spent proportionately less time than either of the control groups in interactive states of engagement (Down: $p<.001$; typical: $p<001$ ). No differences were found between the controls. Within-group paired samples t-test suggested that whereas the children in the control groups spent more time in interactive versus non-interactive 
engagement states (Down: $t=4.1(11), p<.01$; TD: $t=5.3(11), p<.001$ ), the opposite was the case for those in the ASD group, who spent a greater proportion of their time in non-interactive, as opposed to interactive, engagement states, $t=3.0(11), p<.005$.

\section{a. Discussion}

\section{Summary of findings}

Parents of children with ASD initiated proportionately fewer invitations to act on an object andi made more bids physically eliciting their child's attention to, or action on, an object, relative to parents of children in the comparison groups. Whilst invitations to act on an object were by far the niost commonly observed category of parent invitation in all groups, they comprised only $60 \%$ of initictions made by the parents of children with autism, compared to nearly $80 \%$ of those produced by the parents of both control groups. In contrast to the children in the DS and TD groups, those with ASD were proportionately less likely to comply with, or elaborate on, their parent's invitations and proportionately more likely to ignore them, either because they were engaged in anon-object centred act (e.g. selfinvolved stereotypies, staring into space, moving around the room), or preoccupied with their own particular use of an object. Further qualitative analysis of responses coded in the category 'own act with an object' indicated that a mean of $45 \%$ of those produced by the children with ASD were coded as behaviours that would preclude the sharing of an object with another person, compared to only $3 \%$ and $4 \%$, respectively, of the responses of the TD and DS children. In addition, state-based analyses indicated that the children with ASD spent a lower proportion of their total play time jointly engaged with their parent and an object and inore time unengaged, or focussed exclusively on their own use of an object, relative to chilaren in the comparison groups.

\section{The social mediation of object use}

The finding that almost four fifths of all bids initiated by parents in the TD and DS groups comprised invitations to use an object in a conventional manner, suggest that triadic interactions provide a context within which caregivers, as more culturally experienced members of society, shape their children's actions on objects in socially appropriate ways (Costall \& Dreier, 2006; Valsiner, 1987). It is consistent with Costall's (2012) argument that human artefacts have a conventional, normative and objectified status, with the 'use-meanings' of things residing not at the level of the object 
or individual parent-child dyad, but in the wider social network of shared cultural practices. The largely positive responses shown by the non-autistic children to such guidance are also consistent with Valsiner's (1987) claim that this process of social mediation is entered into willingly by the child. These findings also resonate with parents reported experiences of introducing their children to the 'proper' use of objects, used in everyday routines, such as a toothbrush (Williams et al., 2005). Parents of TD children and those with DS in this study both described their child's active participation in this process, including their evident desire to use a particular object when seeing someone else do so and their initiation of the introduction of an object by asking for it. For these children, parents clearly afford guidance and shaping of object use.

In contrast, the distinctly different pattern of findings obtained in the context of triadic play for those dyads involving a child with ASD points to a disturbance in this process of social mediation. Not only did these children predominantly respond by showing no interest in their parent's efforts to get them to act on/attend to an object, either because they were preeccupied with their own particular use of an object or because they were absorbed in their own non-object centred action, but they were also less likely to react to a parent's invitation by complying or elaborating on it. Hence, the children with autism did not appear to perceive their parents as affording guidance in how to use objects to the same extent as the typical children and chilaren with Down syndrome did. Furthermore, the parents themselves were less likely ihan those jin the comparison groups to invite their child to use an object in a conventional fashion, suggesting that they, in turn, may have come to perceive their children as offering less possibilities for guidance in relation to objet use compared to parents of the other groups. The actions of the parent and child are inter-dependant and it is likely that the relatively greater propsition of invitations that physically elicited attention to/action on an object made by the parents of the childyen with ASD is an adaptive response to the repeated lack of interest show by their child. This Conclusion is supported by Williams et al.'s (2005) finding that parents of children with autism who reported experiencing a greater number of problems in introducing the culturally specific use of various everyday objects than did parents of non-autistic children, cited their child's failure to copy other people's actions on objects, and their apparent lack of interest in doing so, as the reason why they 
needed to use more intensive and repeated training, including hand-over-hand physical guidance, to elicit an 'appropriate' response.

Analysis of the time spent by the dyads in various engagement states showed that those involving children with ASD spent a smaller proportion of their total play time in states that would clearly enable the parent to shape their use of an object in conventional ways (i.e. joint and supported engagement) and, conversely, more time in states that would prevent it (i.e. unengaged, object). This was the reverse of the pattern found in the dyads involving TD children and children with DS. Previous researcir has shown that children with ASD tend to make fewer invitations to other people to share anobiect vith them, which would limit still further their opportunities for entering into situations where the shared meaning of objects is negotiated (Mundy et al., 1990). Taken collectively the findings drawn from the event-and state-based analyses support our contention that the opportunities for children with autism to pick up the social conventions surrounding object use in the course of their object-centred interactions with their parents are more limited than is the case for TD chlidren and children with DS. This may, at least in part, explain the developmental delay in using objects appropriately found by Rowland \& Schweigert (2009). If there is less opportunity for a child with autism to be guided in their use of commonplace objects by other people, finen it follows that their acquisition of the conventions surrounding these objects will, at the very least, be slower than those of children for whom this is not the case.

\section{Idiosyncratic object use}

Much research has already documented the disturbing impact that difficulties in shifting gaze between people and objects (Landry \& Loveland, 1988; Swettenham et al., 1998) and in using joint attention gestures to invite other people to share an object (Mundy et al., 1990; BaronCohen, et al., 1992; Bruinsma et al., 2004) have on the capacity of the young child with autism to enter into and maintain triadic interactions. However, relatively little attention has been paid to the childobject relations themselves as a possible source of disruption. The findings in this study that the children with ASD spent proportionately more of their time in exclusive engagement with an object and produced a greater proportion of responses coded in the category 'own act with an object', relative to developmentally matched controls, suggests that the child-object component of the joint 
engagement triangle may also be problematic. It appears that for the child with autism, with their own distinctive physical and psychological effectivities, objects often afford quite a different possibility for action than they do for their parent. In this case, when affordances are not mutual, it is not surprising that objects disrupt, rather than mediate, joint engagement. Moreover, further analyses of the category of responses 'own act with an object' as preclusive or non-preclusive, suggest that the kind of actions particular objects, or parts of them, afford a child with autism (e.g the wheels of a toy car afford continual spinning) make it extremely difficult for the parent to get their child to attend to the conventionally shared use-meaning of the same object (e.g. run the car along the ground), or for them to re-direct their child's attention to a different cbject that they want them child to engage with. When engaged in actions such as focussing on a single part of an object for an extended period of time, becoming intensely absorbed in a single property, such as texture, or holding an object close to the eye and twisting it (perhaps to observe the changes in lighting?), the child does not afford being guided by the parent, limiting opportunities for the parent to shape their object use in conventional ways. This is consistent with the work of Bruckner and Yoder (2007), who found that the restricted object use of young children with autism was linked to a decreased likelihood of paying attention to the attentional cues, prompts and demonstrations of an adult. This has very important implications for the child's development if, as Palacios \& Rodríguez (2015) present compelling evidence to suggest, symbolic play is grounded in predictable and conventional uses of objects, particularly in the context of play with caregivers. This may help explain the difficulties children with autism have with engaging in pretend play without the need to resort to the kind of hypothetical cognitive structures proposed by proponents of the 'Theory of Mind'(Leslie, 1987) approach to autism.

In addition to those behaviours that were identified prior to the study as being likely to preclude interaction with another person, subsequent analysis of the videotapes revealed additional behaviours that may also function to prevent the establishment of shared action or attention around an object. One such behaviour was the repetition by the child of an action, initially demonstrated by the parent, to the extent that it came to interfere with subsequent attempts made by the parent to get the child to act on, or attend to a different object. For example, in one case the parent set up some of the objects in such a way 
as to form a steep ramp, that she then ran a car down. The child imitated this action, and then proceeded to repeat it for the majority of the play session, ignoring the ensuing parental invitations to engage him with other objects. In the end the parent dismantled the 'ramp' after which the child took the car to a table and proceeded to try and achieve the same effect by dropping it from the table top and catching it in his hands. Another striking example of such behaviour was observed outside of a videotaped session. The parent put some water in a teapot and proceeded to show the child how to pour it into a cup. The child repeated his activity endlessly for the rest of the time that we were in the house. Two weeks later, during a telephone conversation with one of the investigators, the parent reported that the child had continued performing the same activity obsessively during the intervening weeks. Whilst repetition of actions initially demonstrated by parent did occur in the comparison groups, these were more easily punctuated by a parent's invitation to carry out different actions/attend to other objects and 1n not being so frequent. Given the observation of these behaviours that also function to bleck the child perceiving other possibilities for action with an object, or their parent as a afferding guidance in its use, it is likely that the $45 \%$ of behaviour coded as preclusive in children with autism is a conservative estimate of the proportion of 'own acts with an object' that actually serve to make it very difficult, for the parent to engage the child through an object.

Consistent with the findings in this study, when questioned about their child's use of everyday objects (Williams et al., 2005), only parents who had children with autism reported that their child's odd use of certain objects, or interest in isolated aspects of an object, interfered with attempts to get the child to use an object in an appropriate way. In other words, rather than the physical form of an object providing ain additional. source of cultural influence that helps to shape the child's action in conventional ways, the child's perception of different affordances in objects to those of the parent becomes a barrier to the introduction and maintenance of appropriate object use by the caregiver. If it is the case, as evidence from this study suggests, that some of the ways in which children with autism perceive and relate to objects disrupt triadic interaction, developmental ecological work in this area could help inform the development of intervention strategies centred on interactions around objects, by investigating and describing the affordances of objects for children with autism. Such work could help identify which objects best mediate interactions in parent-child with autism dyads so that 
such contexts could still function in terms of facilitating development. The findings presented suggest that conventional toys which invite actions relating to shared cultural practices and objects which afford such an intense focus that they preclude sharing will not be effective. On the basis of such information it may also be possible to train caregivers in the context of a play situation to recognise the affordance that particular objects may have for their child, so that in that moment it becomes a mutual affordance which mediates rather than disrupts engagement. A similar intervention programme proved successfui with blind children and their parents, where the parent was trained to appreciate that the possibiiities for action that objects afforded to their child were tactile rather than visual (Fraiberg, 1977). Researsh is also needed into how play evolves over time between parents and children with autism.

\section{Conclusion}

In stressing the problems young children with ASD have in using objects in a conventional manner, it has not been the purpose of this paper to play dewn the social dimension of autism in favour of a material one. Rather, the aim has been to challenge the rigid dualism between the social and the material that underlies most current theories of autism. It is suggested that those theories of autism deriving from the 'Theory of Mind' approaci fail to make the link between difficulties in understanding others and relations to things, as a resilt of a failure to appreciate fully the importance of social mediation, including various aspects of joint attention, in the education of the child's attention towards the function of things Crallenging this rigid social-material divide necessarily involves questioning the restricted use gif the term 'social' as referring only to relations to other people. In highlighting the reciprocal naturg of the interactions between the child, other people, and objects, the findings presented here indicate that relations to objects cannot be considered outside of the social context in which they are introduced and used. Nor can they be examined apart from the human activities they shape in common ways. Furthermore, this is not simply a theoretical problem, but also a practical one. If we are to devise successful interventions for individuals with autism it is essential that we fully appreciate the interpenetration between different areas of development, including the child's dealings with objects and other people. It is precisely for this reason that what people actually do and the material resources that support this activity should be a matter of serious concern to psychologists, and why more attention 
needs to be paid to the psychological significance of objects themselves. Ecological developmental psychology, with its focus on the material conditions of action, is well placed to do some important work in this area. 


\section{References}

Adamson, L.B. \& Bakeman, R. (1985). Affect and attention: Infants observed with mothers and peers. Child Development, 56, 582-593.

American Psychiatric Association (1994). Diagnostic and statistical manual of mental disorders. (4th ed., rev.). Washington DC: American Psychiatric Association.

Asperger, H. (1944). Die 'Autistischen psychopathen' im kindesalter. Archiv für Psychiatrie und Nervenkrankheiten, 117, 76-136.

Astington, J. W. (1994). The child's discovery of the mind. London: Fontana Fress.

Bachevalier, J. (1994). Medial temporal lobe structures and autism: a review of clinical and experimental findings. Neuropsychologia, 32, 627-648.

Bakeman, R. \& Adamson, L. B. (1984). Co-ordinating aitention to people and object in motherinfant and peer-infant interaction. Chila Development, 55, 1278-1289.

Baron-Cohen, S. (2008). Theories of the autistic mind. The Psychologist, 21(2), 113-116.

Baron-Cohen, S. (1995). Mindblindness: in essay on autism and theory of mind. Cambridge, MA: The MiT Press.

Baron-Cohen, S.. A.lien, J., \& Gillberg, C. (1992). Can autism be detected at 18 months? The neecile, thit haystack and the CHAT. British Journal of Psychiatry, 161, 839-843.

Barcn-Cohen, S. (1989a). Joint-attention deficits in autism: Towards a cognitive analysis. Development and Psychopathology, 1, 185-189.

Baron-Cohen, S. (1989b). Perceptual role-taking and protodeclarative pointing in autism. British Journal of Developmental Psychology 7, 113-127. 
Baron-Cohen, S. (1987). Autism and symbolic play. British Journal of Developmental Psychology, 5, 139-148.

Bayley, N. (1993). Bayley Scales of Infant Development, Second Edition, San Antonio, Harcourt Brace.

Blanc, R., Adrien, J. L., Roux, S. \& Barthélémy, C. (2005). Dysregulation of pretend play and communication development in children with autism. Autism, 9(3), 225-241.

Bruner, J. (1982). The organisation of action and the nature of adult-infant transaction. Ir E. Trenick (Ed.), Social interchange in infancy: Affect, cognition, and communication. Balimore: University Park Press.

Bruner, J. (1975). The ontogenesis of speech acts. Journal of Child Language, 2, 1-19.

Bruinsma Y, Koegel R. L \& Koegel L.K. (2004). Joint attention and children with autism: A review of the literature. Mental Retardation and Developmental Discubilities Research Reviews, 10, 169-175.

Bugrimenko, E. A. \& Smirnova, E. O. (1992). Paradoxes of children's play in Vygotsky's theory. In G. C. Cupchik \& J. Laszlo (Eds.), Emerging visions of the aesthetic process (pp. 286-299). New York: Cambridge University Press.

Cohen, J. (1960). A coefficienı of agreement for nominal scales. Educational and Psychological Measurement, 20(1), 37-46.

Costall, A. P. (251/2). Avant: Trends in interdisciplinary studies, 3(2), 85-93.

Costall, A P. (1995). Socialising affordances. Theory and Psychology, 5, 467-482.

Costall, A. \& Dreier O. (2006). Doing things with things: The design and use of everyday objects. Aldershot: Ashgate Publishing.

Dawson, G. \& Lewy, A. (1989). Arousal, attention, and the socioemotional impairments of individuals with autism. Autism: nature, diagnosis, and treatment, (pp. 49-74). New York: Guildford. 
Dawson, G., \& Adams, A. (1984). Imitation and social responsiveness in autistic children.

Journal of Abnormal Child Psychology, 12, 209-225.

Elison, J. T., Wolff, J. J., Reznick, J. S., Botterton, K. N. Estes, A. M. Gu, H., Hazlett, H. C., Meadows, A.J., Paterson, S. J., Zwaigenbaum, L. \& Piven, J. (2014). Repetitive behaviour in 12-month-olds later classified with autism spectrum disorder. Journal of the American Academy of Child and Adolescent Psychiatry, 53(11), 1216-1224.

Fenson, L., Dale, P.S., Reznick, J.S., Thal, D., Bates, E., Hartung, J.P, Pethick, S., \& Reiny, J.S. (1993). MacArthur Communicative Development Inventories. San Diego, California: Singular Publishers.

Field, A. (2009). Discovering statistics using SPSS, London; Sage.

Fraiberg, S. (1977). Insights from the blind, London: Souvenir

Freeman, B. J., Guthrie, D., Ritvo, E., Schroth, P., Glass, R. \& Erankl, F. (1979). Behaviour observation scale: Preliminary analysis of the similarities and differences between autistic and mentally retarded children. Psychological Renorts, 44 519-524.

Frith, U. (1989). Autism: Explaning the enigma. Oxford: Basil Blackwell.

Gibson, J. J. (1979). The ecolcgicai approach to visual perception. Boston: HoughtonMifflin.

Gillberg, C., Ehlers, S., Schuamann, H., Jakobsson, G., Dahlgren, S.O., Lindblom, R., Bagenholm, A., Tjuus, T., \& Blidner, E. (1990). Autism under age 3 years: A clinical study of 28 cases referred for autistic symptoms in infancy. Journal of Childhood Psychology and Psychiatry, 31, 921-934.

Girolametto, L. Verbey, M., \& Tannock, R. (1994). Improving joint engagement in parent-child interaction: An intervention study. Journal of Early Intervention, 18(2), 155-167. 
Happe, F. (1999). Understanding assets and deficits in autism: why success is more interesting than failure. Psychologist, 12, 540-546.

Happe, F. (1994). Autism: an introduction to psychological theory. London: UCL Press.

Hermelin, B \& O'Connor, N. (I 970). Psychological experiments with autistic children. Oxford. Pergamon Press.

Hobson, R. P. (1993). Autism and the development of mind. Hillsdale NJ: Lawrence Eribaum.

Joerges, B. (1988). Technology in everyday life: Conceptual queries. Journal for the Theory of Social Behaviour, 18, 221-237.

Kanner, L. (1943). Autistic disturbances of affective contact. Nerrous Child, 2, 217-250.

Landry, S. H., \& Loveland, K. A. (1988). Communication behavisurs in autism and developmental language delay. Journal of Child Psychology and Psychiatry, 29, 621-634.

Leekam, S. R., Hunnisett, E. \& Moore, C. (1998). 'Targets and cues: Gaze following in children with autism. Journa! of Child Psychology and Psychiatry, 39, 951-962.

Leontiev, A. N. (1981). Problems of the a velopment of mind. Moscow: Progress Publishers.

Leslie, A. (1987). Pretence and representation in infancy: Origins of 'theory of mind. Psychological Review 4. $84-105$.

Lewis C. \& Mitchell, P. (2014). Children's early understanding of mind. Hove, UK: Psychology press.

Lewy, A. L., \& Dawson, G. (1992). Social stimulation and joint attention in young autistic children. Journal of Abnormal Child Psychology, 20, 555-566.

Libby, S., Powell, S., Messer, D. \& Jordan, R. (1998). Spontaneous pretend play in children with autism: A reappraisal. Journal of Autism and Developmental Disorders, 28, 487-497. 
Lieberman R. G. \& Yoder P. (2012). Play and communication in children with autism spectrum disorder: A framework for early intervention. Journal of Early Intervention, 34(2), 82-103.

Loveland, K. A. (1991). Social affordances and interaction II: Autism and the affordances of the human environment. Ecological Psychology, 3, 99-119.

McArthur, D. \& Adamson, L.B. (1996). Joint attention in preverbal children: Autisn and developmental language disorder. Journal of Autism and Developmental Discraers, 26, 481-496.

Mundy, P., Sigman, M., \& Kasari, C. (1990). A longitudinal study of jøint attention and language development in autistic children. Journal of Autism cind Developmental Disorders, 20, 115-128.

Mundy, P., Sigman, M., Ungerer, J., \& Sherman, T. (1987) Non-verbal communication and play correlates of language development in autistic shildren. Journal of Autism and Developmental Disorders, 17, 349-364.

Mundy, P., Sigman, M., Ungerer, J, \& Sherman, T. (1986). Defining the social deficits of autism: The contribution of nor-verbal communication measures. Journal of Child PsychologyanáPsychiatry, 27, 657-669.

Naber, F. B. A.., Bakermar. Kranenburg, M. J., van IJzendoorn, M. H., Swinkels, S. H. N., Buitelaar, J. K.. Dietz. C., van Daalen, E. \& van Engeland, H. (2008). Play behavior and attachment in toddlers with autism. Journal of Autism and Developmental Disorders, 38(5), 857-866.

Ninio, A. \& Bruner, J. (1 978). The achievement and antecedents of labelling. Journal of Child Language, 5, 1-1

Palacios, P. \& Rodríguez, C. (2015). The development of symbolic uses of objects in infants in a triadic context: A pragmatic and semiotic perspective. Infant and Child Development, 24, 23-43. 
Park, C. C. (1983). The siege: The first years of an autistic child with an epilogue, fifteen years after. London: Hutchinson.

Piaget, J. (1952). The origins of intelligence in children. New York, International Universities Press.

Preston, B. (2000). The functions of things: a philosophical perspective on material culture. In P.M. Graves-Brown (Ed.), Matter, materiality and modern culture. (pp. 22-49). London: Roatledge.

Reddy, V., Williams, E. and Vaughn, A. (2002). Sharing humour and laughter in young children with autism. British Journal of Psychology, 93, 219-242.

Richer, J. (1978). The partial non-communication of culture to autistic children: An application of human ethology. In M. Rutter \& E. Schapler (Eds.), Autism: A reappraisal of concepts and treatment (pp. 47-61). New York·Plenım Press

Rocissano, L. (1982). The emergence of social conventional behaviour: evidence from early object play. Social Cognition, 1, 50-69

Rowland, C.M. \& Schweigert, P. D 2009). Object lessons: How children with autism spectrum disorders use objects to interact with the physical and social environments. Research in Autism Spectrum Disorders, 3, 517-527.

Sacrey, L. A., Bryson, s.e., \& Zwaigenbaum, L. (2013). Prospective examination of visual attention during piay in infants at high-risk for autism spectrum disorder: a longitudinal study from 6 to 35 months of age. Behavioural Brain Research, 256, 441-450.

Sigman, M., Mundy, P., Sherman, T., \& Ungerer, J. (1986). Social interactions of autistic, mentally retarded and normal children and their caregivers. Journal of Child Psychology and Psychiatry, 27, 647-656.

Sigman, M. \& Ungerer, J. A. (1984). Cognitive and language skills in autistic, mentally retarded and normal children. Developmental Psychology, 20, 293-302. 
Schopler, E., Reichler, R. J. \& Renner, B. R. (1986). The Childhood Autism Rating Scale, (CARS). New York: Irvington.

Sparrow, S. S., Balla, D. A., \& Cicchetti, D. V. (1984). Vineland Adaptive Behaviour Scales, Interview edition, Circle Pines, Minnesota: American Guidance Service.

Swettenham, J., Baron-Cohen, S., Charman, T., Cox, A. Baird, G. Drew, A., Rees, \& Wheelwright, S (1998). The frequency and distribution of spontaneous attention shifts between social and non-social stimuli in autistic, typically developing an non-autistic developmentally delayed infants. Journal of Child Psychology and Psychiatry, 39, 747653.

Szokolszky A. (2006). Object use in pretend play: Symbolie or functional? In A. Costall \& O. Dreier (Eds.). Doing things with things: The design and use of everyday objects. (pp. 67-87). Aldershot: Ashgate Publishing.

Taylor Bruckner, C. \& Yoder, P. (2007). Restricted object use in young children with autism Definition and construct validity. Autism, 1, 161-71.

Tiegerman, E., \& Primavera, L. (1981). Object manipulation: An interactional strategy with autistic children. Jonrral of Autism and Developmental Disorders, 11(4), 427-438.

Tomasello, M. (1999). The cultural ecology of young children's interactions with objects and artefacts.

In E. Wincgrad, R. Fivush, \& W. Hirst (Eds.), Ecological approaches to cognition: Essays in honour of Ulric Neisser (pp. 153-170). Mahweh, NJ: Lawrence Erlbaum.

Tomasello, M. \& Farrar, M.J. (1986). Joint attention and early language. Child Development, $57(6), 1454-1463$.

Tomasello, M. \& Todd, J. (1983). Joint attention and lexical acquisition style. First Language, 4, 197- 211. 
Trevarthen, C., \& Hubley, P. (1978). Secondary intersubjectivity: confidence, confiding and acts of meaning in the first year. In A. Lock (Ed.), Action, gesture and symbol: the emergence of language (pp. 183-229). London: Academic Press.

Turiel, E. (1978). The development of concepts of social structure: Social convention. In J. Glick \& A. Clarke-Stewart (Eds.). The development of social understanding. New York: Gardner Press.

Ungerer, J.A. \& Sigman, M. (1981). Symbolic play and language comprehension in autistic children. Journal of the American Academy of Child Psychiatry, 20, 318 -3?.

Valsiner, J. (1987). Culture and the development of children's action: Actuttiral historical theory. Chichester, Wiley.

van Leeuwen L. \& Westwood, D. (2010). If Winnicott ccuid make toys.... International Journal of Arts and Technology, 3(1), 57-65.

van Leeuwen, L., Smitson, A. \& van Leeuwen, C. (1994) Affordances, perceptual complexity, and the development of tool use, Jourral of Experimental Psychology, Human Perception and Performance, 20(1), 174.91.

Vaughan Van Hecke A, Mundy P. C., Acra, C. F., Block J. J., Delgado C. E, Parlade, M.V., Meyer J. A., Neal A. K. Pomares, Y. B. (2007). Infant joint attention, temperament, and social competence in preschool children. Child Development, 78(1), 53-69.

Volpert, W. (1985). Epilogue. In M. Frese and J. Sabini (Eds.), Goal-directed behaviour: the concept of action in psychology (pp.357-365). Hillsdale, NJ: Lawrence Erlbaum.

Vygotsky, L. S. (I 978). Mind in society. The development of higher psychological processes, Harvard University Press, Cambridge, Massachusetts.

Wetherby, A. M. \& Prutting, C. A. (1984) 'Profile of Communicative and Cognitive-Social Abilities in Autistic Children'. Journal of Speech and Hearing Research, 27, 367-377. 
Williams, E. (2003). A comparative review of early forms of object-directed play and parent-infant play in typical infants and young children with autism. Autism: International Journal of Research and Practice, 7, 361-377.

Williams, E. \& Costall, A. (2000). Taking things more seriously: psychological theories of autism and the material-social divide. In Graves, P. (ed.), Past and Present: Modern Material Culture, Routledge, London.

Williams, E, Costall, A. \& Reddy, V. (1999). Children with autism experience prsblems with both objects and people. Journal of Autism and Developmental Disorders, 29, $3607,378$.

Williams, E., Kendell-Scott, L. and Costall, A. (2005). Parents' experiences of intrưulucing everyday object use to their children with autism. Autism: International Journal of Research and Practice, 9(5) 521-540.

Williams, E., Reddy, V. \& Costall, A. (2001). Taking a closer look at functional play in children with autism. Journal of Autism and Developmentat Disorder, 31(1), 67-77.

Wilson, K. P., Carter, M. W., Wiener, H. L., Deramus, M. L., Bulluck, J C., Watson, L. R., Crais, E. R. \& Baranek, G. T. (2917). Object play in infants with autism spectrum disorder: A longitudinal retrospective video analysis. Autism and Developmental Language Impairments, 2, 1-12.

Wimmer, H., \& Perner $\mathbf{J}$ (1983). Beliefs about beliefs: Representation and constraining function of wrorig beliefs in young children's understanding of deception. Cognition, 13(1), 103-28.

Wing, L, (1969). The handicaps of autistic children - A comparative study. Journal of Child Psychology and Psychiatry, 10, 1-23.

World Health Organisation. (1990). International Classification of Diseases, 10thedn. Diagnostic Criteria for Research (draft). Geneva: WHO. 


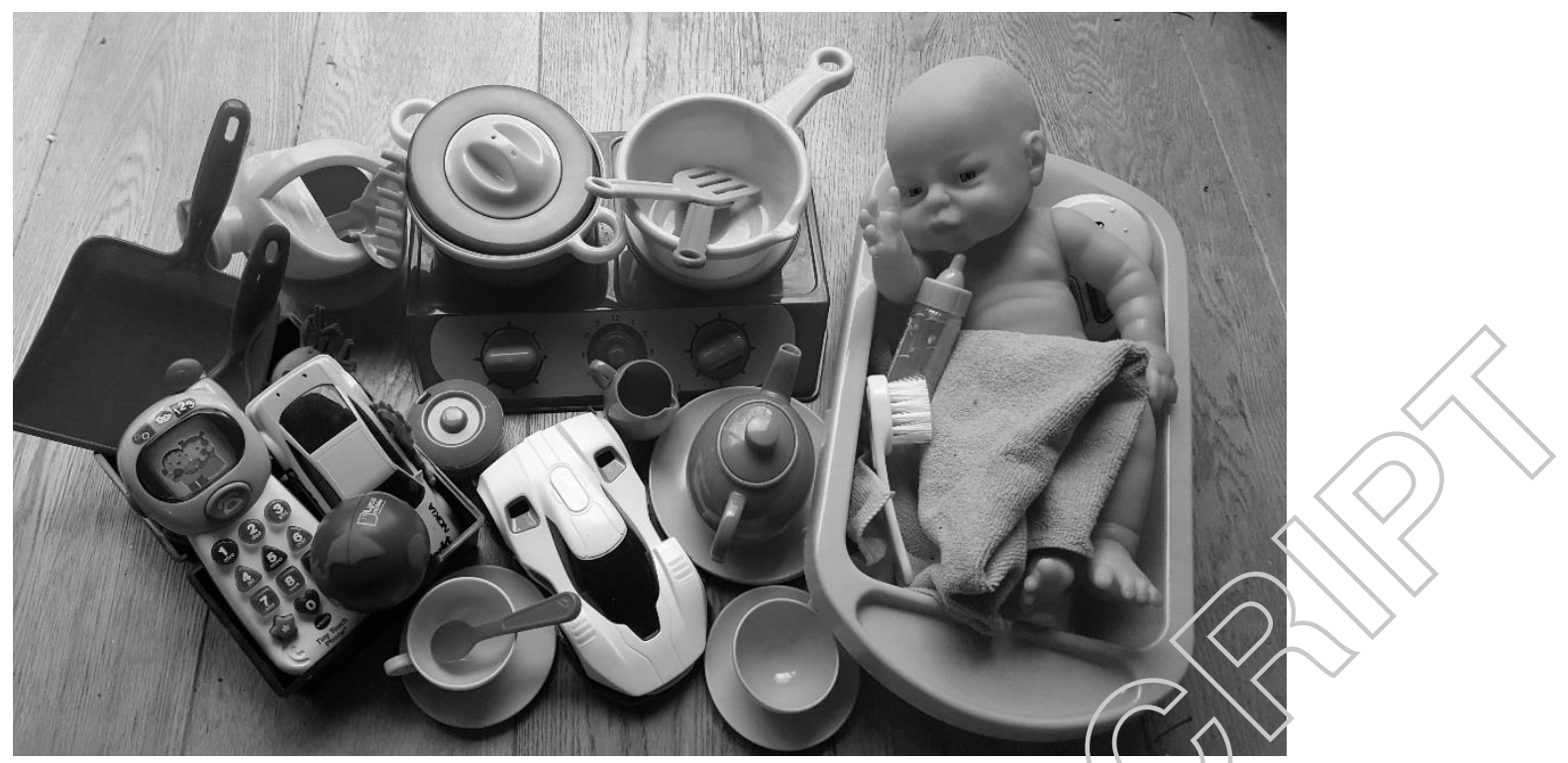

Figure 1: Toys used in play sessions

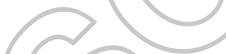


Figure 2: Mean proportions and standard deviations of parent invitations, by group and type of invitation

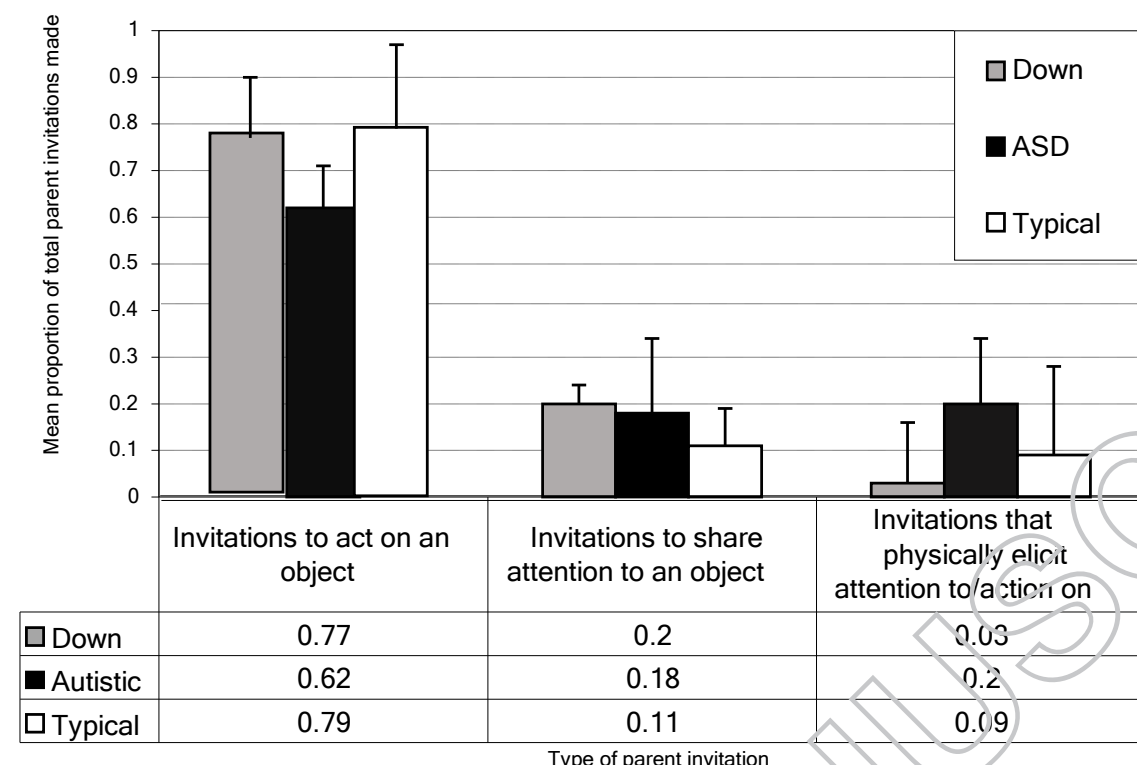

Figure 3: Mean proportion of total child esponses to parent invitations to act on an object, by type of response and group

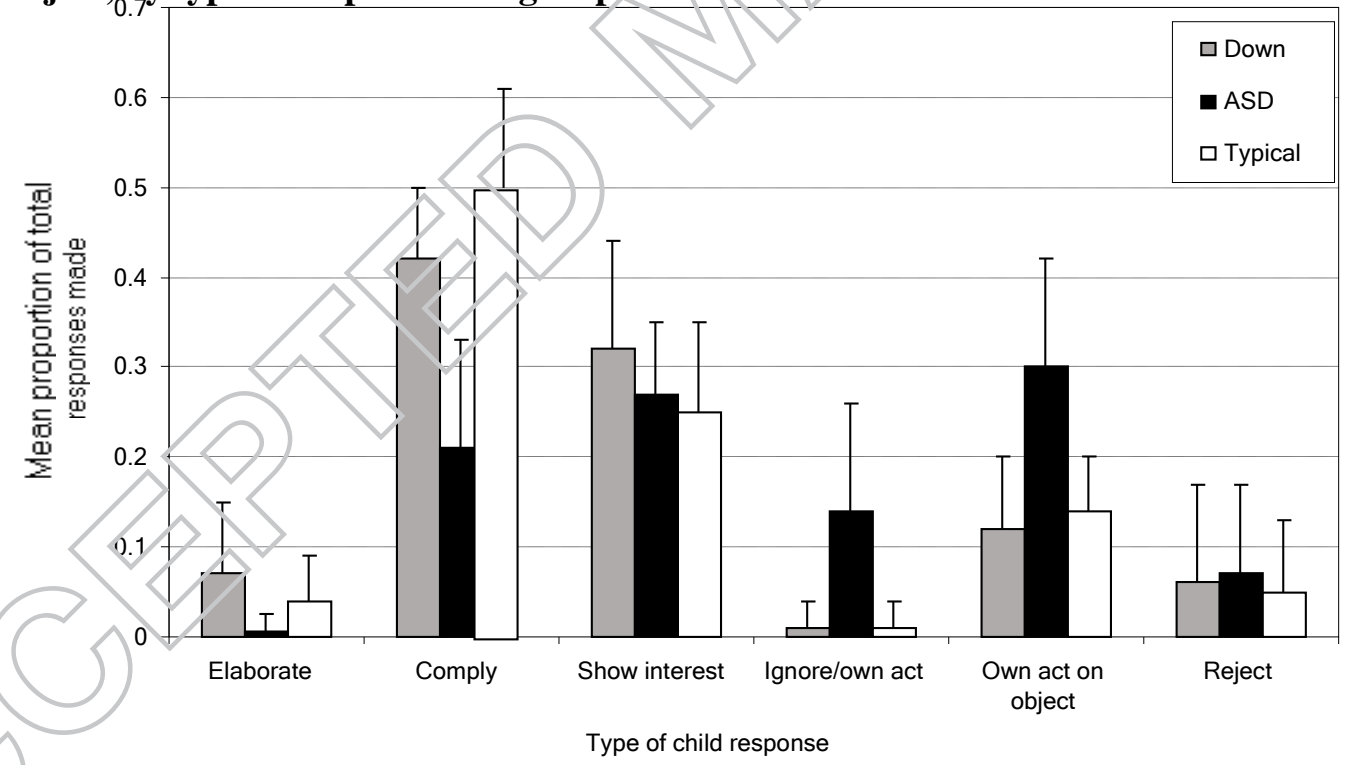


Figure 4: Mean proportions ot total play time spent in each engagement state by group assignment

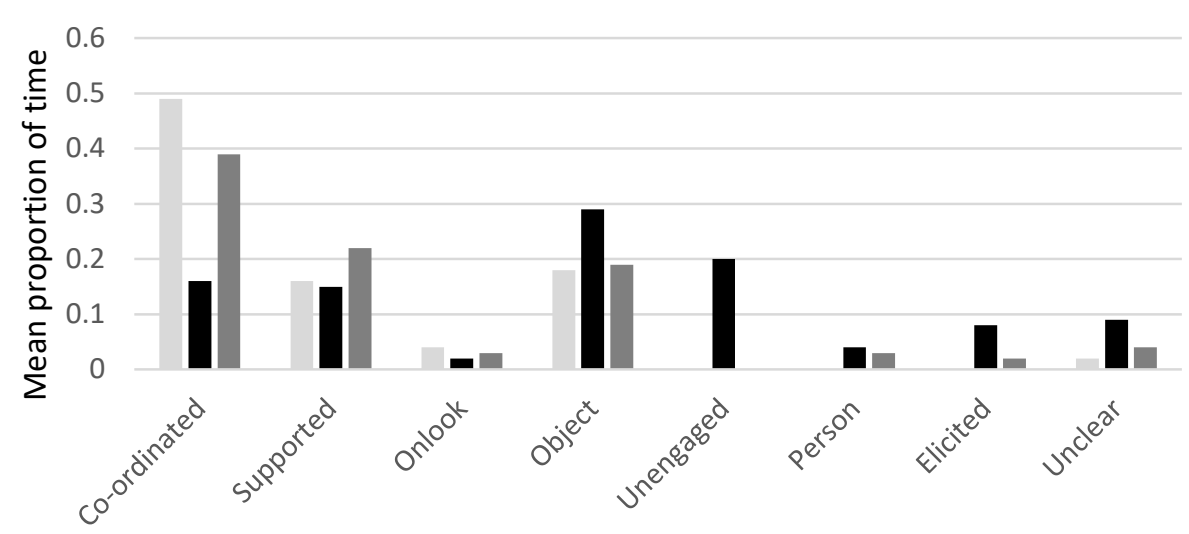

Engagement state

Table 1 Participant Characteristics

\begin{tabular}{|l|l|l|l|}
\hline & Down & Autistic & Typical \\
\hline$N$ & 12 & 12 & 12 \\
\hline Male/female & $9 / 3$ & $10 / 2$ & $8 / 4$ \\
\hline Chronological age (months) & & & \\
\hline$M$ & 42.8 & 50.1 & 18.6 \\
\hline$S D$ & 15,1 & 6.9 & 4.9 \\
\hline Range & $18--72$ & $36--62$ & $13--26$ \\
\hline Bayley developmental age (months) & & & \\
\hline$M$ & 17.9 & 18.2 & 18.6 \\
\hline$S D$ & 4.1 & 4.3 & 5.3 \\
\hline Range & $13--29$ & $12--26$ & $11--29$ \\
\hline Vineland \& MacArthur Receptive Laingage (months) & & & \\
\hline$M$ & 18.7 & 17.0 & 18.1 \\
\hline$S D$ & 5.2 & 8.0 & 6.0 \\
\hline Range & $12--30$ & $8--30$ & $9--30$ \\
\hline & & & \\
\hline
\end{tabular}

Table 2: Description of event-based coding scheme as a function of parent-initiated events and their child's responses to these initiations

\section{Coae Brief definition and examples}

\section{PARENT-INITIATED EVENTS}

\section{Invitations to act on an object}

A parent demonstrates an act with an object to their child, e.g. pushing a toy car along the ground or drinking from a cup. This includes cases where a

Demonstrate parent simply demonstrates a particular act with an object and those where they include a verbal suggestion to their child that they perform this action, e.g. putting a doll in the bath and then saying 'you do it now.' 
A parent verbally suggests that their child carry out a particular act with an

Suggest object, but does not demonstrate this act themselves, e.g. saying 'are you going to put the doll in the bath?' or handing a spoon and pot to the child, saying are you going to stir the food in the pot?

Invitations to share attention to an object

A parent brings a particular object, or new aspect of an object, to their child's attention by pointing at it, commenting on it, offering it to the child, or using Draw any conventional gesture designed to draw the child's focus of attention, but attention does not act on the object themselves, e.g. pointing at a doll and saying 'look can you see the doll?' or holding out a doll towards the child in order to show it to them.

Question A parent asks a child a question about an object, e.g. 'what's this?' or 'what colour is this?'

\section{Invitations that physically elicit attention to/action on an object}

Physically

A parent physically shapes their child's action on an object, e.g. putting their

structure

hands over the child's hands and moving the child's arms to perform a certain activity.

A parent highlights a particular visual, auditory, or tactile pionerty of an

Physically object in order to draw the child's attention to it, e.g. ticiling their child with a

elicit attention brush, or shaking the hair of a doll in their child's visual fictd It also includes holding a desired object out of the child's reach.

\section{CHILD RESPONSES TO PARENT INITIATIONS}

\section{Responses showing no interest}

The child physically rejects their parent's invitation or direction, e.g. walking

Reject

out of the room, pushing their parent a vay, beroming upset, shaking their head or saying no.

The child appears to ignore their parent's invitation, e.g. looking away from the parent, staring into space, or giving the object only a brief glance (less

ignore/Own than 3 seconds) before turning avay. This also includes cases where the child

act ignores their parent because they are engaged in their own act that does not involve an object, e.g. sucking their thumb, twiddling with their hair or visually scanning the environment (possibly whilst moving).

A child pays ne attention to the invitation of their parent because they are engaged in their own action on an object, e.g. where the parent shows the

Own act with an object child what they can do with a cooker, but the child ignores this and continues biting on a rubber ball, or where a parent points out a doll to the child, the child briefly glances at the doll ( 2 seconds or less) and then goes back to tarping on a plate. These behaviours were further subdivided according to whether they would preclude interaction or not:

Preclusive versus non-preclusive - An act is coded as preclusive if the child brings an object close to their eyes in order to inspect it, becomes engrossed in feeling, smelling or mouthing an object, or focuses on a single aspect of an object for an extended period of time (more than 10 seconds), such as the wheel of a car.

\section{Responses showing interest}

A child passively watches a parent's direction as to how to act on an object, or

Look looks at a particular object when invited to (for longer than 3 seconds) but does not act on the object.

A child complies with their parent's direction to act on an object in a particular 
stirring the spoon around a pot after a parent has suggested this activity. A response to an invitation to share attention, or that physically elicits attention, to an object is coded in this category if the child then acts voluntarily on the object to which they have been directed, e.g. the parent says 'look a car!' and the child gets the car and pushes it along the ground.

A child extends their parent's direction of how to act on a particular object in an appropriate way, continuing an already established scheme, e.g. the parent suggests putting a saucepan on the cooker. The child complies with this suggestion and then puts a carrot in the saucepan (an action not suggested by

Elaborate the parent). A response to an invitation to share attention, or that physically elicits attention to an object, is coded in this category if the child acts on the object to which their attention has been drawn in such a way as to involve their parent in a new act or extends an already established game/scheme. C.g. the parent points to a doll and the child gets the doll and a bath and says 'wash dolly, mummy'.

Table 3: Description of state-based coding scheme by engagement state

\begin{tabular}{|c|c|}
\hline $\begin{array}{l}\text { Brief } \\
\text { definition and } \\
\text { examples }\end{array}$ & \\
\hline Unclear & $\begin{array}{l}\text { The state cannot be coded, as the child, narent, or both, are out of camera } \\
\text { shot. }\end{array}$ \\
\hline Unengaged & $\begin{array}{l}\text { The child shows no evidence of sustained engagement with either their } \\
\text { parent or an object, e.g. they niay be visually scanning the environment, } \\
\text { self-involved in sterevtypies, such as hair twiddling, or rocking backwards } \\
\text { and forwards. }\end{array}$ \\
\hline Person & $\begin{array}{l}\text { The child is actively engaged exclusively with their parent with no } \\
\text { objects being involyed, e.g. playing peek-a-boo, or singing a nursery } \\
\text { rhyme shyme. }\end{array}$ \\
\hline Object & $\begin{array}{l}\text { The child plays with an object on their own to the exclusion of the parent, } \\
\text { e.g turning the wheels of a car or stirring in a pot, without looking at or } \\
\text { involving their parent. It includes cases where a child might have } \\
\text { previously engaged with their parent but then excludes them by putting } \\
\text { the object close to their eyes, or physically turning away. }\end{array}$ \\
\hline & $\begin{array}{l}\text { The child watches the activity of their parent, but takes no part in it } \\
\text { themselves and does not smile, vocalise, reach towards the object or } \\
\text { show any animation. }\end{array}$ \\
\hline Ejicited & $\begin{array}{l}\text { The child involuntarily assumes their parent's focus of attention. This } \\
\text { includes inter- active episodes depending heavily on parental elicitation of } \\
\text { the child's attention to an object, e.g. where the parent tickles the child with } \\
\text { a brush, holds an object close to the child's face, or withholds a toy to } \\
\text { prompt a request. It also includes case,' where the child's action on an }\end{array}$ \\
\hline
\end{tabular}




\begin{tabular}{|c|c|}
\hline & object is physically directed by their parent (e.g. hand over hand). \\
\hline Supported & $\begin{array}{l}\text { The child actively attends to an object that is also the focus of the parent's } \\
\text { attention, but does not produce any overt behaviour as evidence that they } \\
\text { are aware of their parent's involvement. This includes cases where an adult } \\
\text { demonstrates an action or shows a child an object and the child shows their } \\
\text { involvement through smiling, laughing, reaching, vocalising or exploring } \\
\text { the object. Tum-taking games were coded in this category unless the child } \\
\text { repeatedly looks between the parent and the object. }\end{array}$ \\
\hline Co-ordinated & $\begin{array}{l}\text { The child is primarily involved with the object with which their parent is ais } \sigma \\
\text { engaged }\end{array}$ \\
\hline \multirow[t]{6}{*}{ Engagement } & $\begin{array}{l}\text { and actively co-ordinates attention to the parent with attention/action with } \\
\text { an object/objects. In other words at some point during the joint } \\
\text { engagement the child directs some overt behaviour towards their partner } \\
\text { as evidence that they are aware of their involvement This could include } \\
\text { any of the following: }\end{array}$ \\
\hline & $\begin{array}{l}\text { (1) alternating gaze to object and parent's face, at lecist wice, e.g. the child } \\
\text { pushes a car back to their parent after the parerit has pushed it to them and } \\
\text { looks back and forth between the car and the parent's face; }\end{array}$ \\
\hline & $\begin{array}{l}\text { (2) clearly following the parent's verbal instructions, e.g. the parent asks the child } \\
\text { to put a carrot in the pot and stir it round and the child carries out both actions; }\end{array}$ \\
\hline & $\begin{array}{l}\text { (3) directing appropriate vocalisations about the object to the parent, } \\
\text { e.g. 'the cooker's hot, isn't it munimy? }\end{array}$ \\
\hline & $\begin{array}{l}\text { (4) carrying out an action that elaiborates on an on-going theme/game, e.g. } \\
\text { the parent suggests that they covk some dinner, twiddling the knob of the } \\
\text { cooker, and the child then gets a pot and starts stirring the spoon around. }\end{array}$ \\
\hline & $\begin{array}{l}\text { (5) initiating shared engagement with an object or sharing an action on an } \\
\text { object with, their parent, e.g. pointing to a car and looking at their parent. }\end{array}$ \\
\hline
\end{tabular}

Table 4: Mean proportion of each child response to parent invitations by group assignment and type of parent invitation 


\begin{tabular}{|c|c|c|c|c|c|c|c|c|c|c|}
\hline & \multicolumn{2}{|c|}{ Down } & \multicolumn{2}{|c|}{ ASD } & \multicolumn{2}{|c|}{ Typical } & \multicolumn{4}{|c|}{ Mann-Whitney } \\
\hline & $\mathbf{M}$ & S.D & $\mathbf{M}$ & S.D & $\mathbf{M}$ & S.D & $\bar{U}$ & $p$ & $U$ & $p$ \\
\hline $\begin{array}{l}\text { Invitations to act } \\
\text { on an object }\end{array}$ & & & & & & & & & & \\
\hline Reject & .05 & .11 & .07 & .10 & .05 & .08 & & & & \\
\hline Own act & .01 & .03 & $.14 *$ & .12 & .01 & .03 & 16.0 & $<.05$ & 29.0 & $<.05$ \\
\hline Own Object & .12 & .08 & $.30 * *$ & .12 & .14 & .06 & 16.5 & $<.001$ & 16.0 & $<501$ \\
\hline Show interest & .32 & .12 & .27 & .08 & .25 & .10 & & & & \\
\hline Comply & .42 & .12 & $.21 * *$ & .12 & .49 & .11 & 11.0 & $<.001$ & 5.5 & .081 \\
\hline Elaborate & .07 & .08 & $0^{*}$ & .0 & .07 & .02 & 35.5 & $<.05$ & $\overline{37.6}$ & $<.05$ \\
\hline $\begin{array}{l}\text { Invitations to share } \\
\text { attention to an } \\
\text { object }\end{array}$ & & & & & & & & & & \\
\hline Own act & .04 & .10 & .12 & .16 & 0 & 0 & & & & \\
\hline Own Object & .22 & .21 & $.39 *$ & .23 & .09 & 21 & & & 24.5 & $<.005$ \\
\hline Show interest & .34 & .25 & .30 & & .46 & .45 & & & & \\
\hline Comply/ Elaborate & .40 & .21 & $.18 *$ & .23 & .43 & .42 & 32.0 & $<.05$ & & \\
\hline $\begin{array}{l}\text { Invitations that } \\
\text { physically }\end{array}$ & & & & & & & & & & \\
\hline Reject & & .13 & $.26 *$ & .39 & .10 & .18 & 42.0 & $<.05$ & 45.5 & $<.07$ \\
\hline $\begin{array}{l}\text { elicit attention } \\
\text { to/action on an } \\
\text { object' }\end{array}$ & & & & & & & & & & \\
\hline Own aci & .14 & .22 & .09 & .19 & 0 & 0 & & & & \\
\hline Own Cbjec & 0 & 0 & $.18^{*}$ & .16 & .06 & .10 & 30.0 & $<.005$ & 37.5 & $<.05$ \\
\hline Show interest & .14 & .22 & .13 & .15 & .45 & .45 & & & & \\
\hline Comply/Elaborate & .67 & .52 & .34 & .30 & .40 & .41 & & & & \\
\hline
\end{tabular}

Note. The child response categories comply and elaborate have been amalgamated in the case of parent invitations to share attention to an object and physically elicit attention to/action on an object, due to the small number of children in any of the groups producing responses that could be placed in the elaborate 
category. The child response category reject for parent invitations to share attention to an object has been omitted for the same reason. $* p<.05 \quad * * p<.001$ 